\title{
Proceeding
}

Performance Analysis Workshop, 2 - 5 April 2013, Alicante, Spain

\section{Reliability \& linearity of an electronic body protector employed in taekwondo games: a preliminary study}

\author{
NIKI TASIKA \\ Department of Physical Education and Sports Science, Kapodistrian University of Athens, Greece
}

\begin{abstract}
Tasika N. Reliability \& linearity of an electronic body protector employed in taekwondo games: a preliminary study. J. Hum. Sport Exerc. Vol. 8, No. Proc3, pp. S622-S632, 2013. An official electronic body protector (EBP) requires both, the necessary degree of accuracy and consistency in securing the same result under similar conditions. The purpose of this study was to assess the repeatability and linearity of a taekwondo EBP. A commercially available EBP that registers the energy $(E)$ of a hit in Joules was placed unfolded on a hard non-deformable surface. Ten potential "hit" areas were marked on the EBP's surface. To simulate kicking conditions a $4 \mathrm{~kg}$ iron shot attached to a switch operated electromagnet was systematically released against the EBP from three randomly selected heights $(1.78 \mathrm{~m}, 1.92 \mathrm{~m}$, and $2.00 \mathrm{~m})$. The shot was released 5 times repeatedly from each height on each of the 10 areas. The procedure was repeated after a 30min interval. Reliability was assessed by the test-retest method using Chronbach's alpha, Guttman split half and ICC, and the coefficient of variation (\%CV). The overall (10 sites pooled together) CV was $4.8 \%$. The CV's for the three heights of release were $5.47 \%, 4.77 \%$, and $4.18 \%$, respectively. For the 10 separate analyses (one for each of the $10 \mathrm{EBP}$ sites) CV ranged from $2.5 \%$ to $11.6 \%$. For the 10 separate analyses (one for each of the 10 trials) CV ranged from $6.8 \%$ to $11.6 \%$. The overall reliability between the 30 trials (across the three heights of release) was: Chronbach's $\alpha=0.979$, single measure ICC $=0.572$, average measure ICC $=0.976(p<0.001)$. Testing revealed that the inter-trial and inter-site reliability of the EBP is poor. Further research is required in testing the reliability of a variety of body protectors used in official competitions today so as to assure fairness among contestants. Key words: EBP, TKD, SCORING, WTF
\end{abstract}

Corresponding author. Department of Physical Education and Sports Science (TEFAA), Kapodistrian University of Athens, 41 EthnikisAntistaseos, 17237 Dafni, Athens, Greece

E-mail: ntasika@phed.uoa.gr

Performance Analysis Workshop, 2 - 5 April 2013, Alicante, Spain

JOURNAL OF HUMAN SPORT \& EXERCISE ISSN 1988-5202

(c) Faculty of Education. University of Alicante

doi:10.4100/jhse.2013.8.Proc3.08

VOLUME 8 | Proc3 | 2013 | S622 


\section{INTRODUCTION}

Taekwondo (TKD) is a popular martial art incorporated at the Olympic sport program since the Sydney 2000 Olympic Games. Olympic TKD competitions are characterized by short, frequent bouts of high intensity body movements, interspersed by low intensity activity and short recovery periods (Matsushigue et al., 2009, Santos et al., 2011). In a typical TKD game the competing athletes apply repetitive defensive and offensive kinetic patterns requiring movement accuracy and maximum muscle strength and power (Pieter \& Heijmans, 2000). A variety of punches and kicks to the torso and the head of the opponent are attempted (Jakubiak \& Saunders, 2008), with the kicks in particular being characterized by high speed (Serina \& Lieu, 1991) and impact force (Pieter \& Pieter, 1995).

Monitoring and recording the different punches and kicks under actual game conditions, is of outmost importance for improving the event technically and tactically. In sports, in general, tests and instruments have been developed to measure critical aspects of performance. For example, these tests include contact mats, accelerometers, force platforms and video analysis (Bobbert \& Van Soest, 1994, Cronin et al., 2004, Jidovtseff et al., 2008, Walsh et al., 2006). In martial arts the estimation of kicking forces is usually performed by 3D accelerometry (Sidthilaw, 1996; O' Sullivan, 2009), air bags (Chiu et al., 2007), force transducers (Gray et al., 1979), and kinematical analysis (O' Sullivan, 2009). However, although these tools provide assessments of high accuracy in a lab setting, their cost, lack of portability, and protocol demanding requirements allow only limited application in field conditions. As a result, this led to the development of several systems of body-wear sensors capable of capturing end-product kinetic parameters (i.e. energy) in complex motor tasks (Heinz et al., 2003, Bao \& Intille, 2004, Kern et al, 2003). Some of these devices are used during TKD competition to provide referees with an objective criterion for assigning points. However, they accepted with ambiguity by trainers and athletes (Navaro et al., 2008). This uncertainty drived the World TKD Federation to support the design of electronic body protectors (EBP) that provide reliable and accurate score identification.

An official electronic body protector (EBP) adopted by the World Taekwondo Federation (WTF) should be capable of registering a valid hit on its surface (i.e. the impact produced by a kick or a punch) irrespective of technique but also with the appropriate sensitivity to discriminate between different weight TKD categories. This requires both the necessary degree of accuracy and consistency in securing the same result under similar conditions. Today, little scientific information is available concerning the use of wearable sensors in martial arts (Chi et al., 2004; Haemaelaeinen et al., 2005) and no reports exist for their validity. Some of these devices measure the impact of a hit in absolute SI units such as Joules or units patented by the manufacturer (Song et al., 2010).

The aim of the present study was to investigate the reproducibility and linearity of a commercially available EBP correctly registering the energy of a hit on its surface. We hypothesized that this device would exhibit (a) high levels of repeatability over a sufficient number of standardized hits, and (b) acceptable levels of linearity (proportionality of readings over a representative number of inputs from the full scale).

\section{METHODS}

\section{Materials}

An EBP was used for the experiment. According to the manufacturer the device contains air channel sensor foam (inlay tube) connected to force sensors which transmit wireless, via bluetooth technology, the energy of a hit in Joules on a compatible software running on a PC. Since no information was available by 
the manufacturer regarding the placement of the sensors, it was assumed that every major portion of the EBP's surface must include a sufficient number of sensors to ensure recording of every possible type and magnitude of hit on it. Ten potential "hit" areas (AIAG, 2005; Smith et al., 2007) were defined and marked on the EBP (Figure 1).

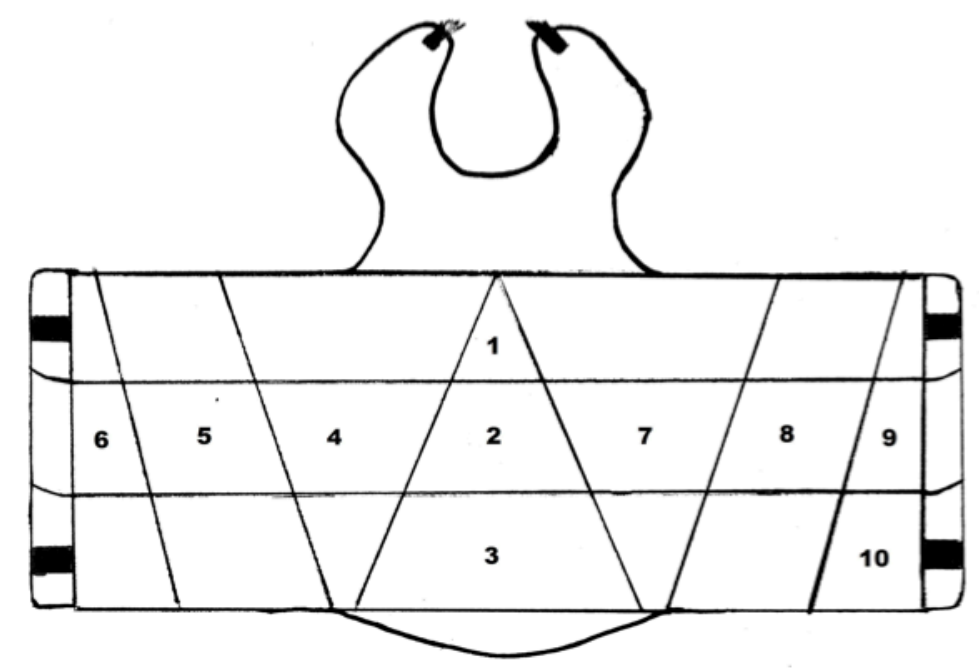

Figure 1. Representation of the 10 EBP surface spots selected for testing

The kicks comprise the majority of the hits in TKD (Kazemi et al., 2010). A kick is usually performed with the instep of the foot but the shank also comes in contact with the opponent. The shank and the foot account for about $1.43 \%$ and $4.61 \%$ of total body mass respectively (Dempster \& Gauhran 1967). This gives a total of $6 \%$, which for an average $70 \mathrm{~kg}$ male corresponds to a $4.2 \mathrm{~kg}$ mass. This "active body mass" acts upon the EBP during a typical kick under a variety of kicking speeds with a final kinetic energy (KE). To simulate these typical kicking conditions a $4 \mathrm{~kg}$ iron shot was selected and was systematically released against the EBP from three randomly selected heights $(1.78 \mathrm{~m}, 1.92 \mathrm{~m}$, and $2.00 \mathrm{~m})$, producing three corresponding KE values (69.84 J, $75.34 \mathrm{~J}$ and $78.48 \mathrm{~J})$. The procedure was carried according to the British standards (British Standards, 2000) guidelines instructing trunk protectors to be placed on a rigid anvil and tested with a rigid impactor.

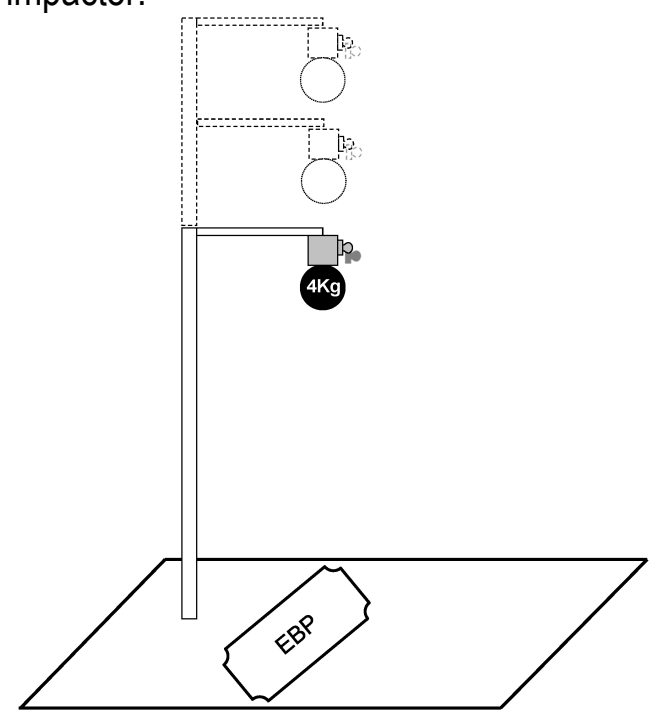

Figure 2. Depiction of the system used at the experimental procedure 
This system included a switch operated electromagnet firmly attached on a pole adjustable in height which was bolted on the ground. The EBP was placed flat and unfolded on the ground upon a hard nondeformable surface to minimize the absorption of energy during the deceleration phase of the strike.

\section{Procedure}

Initially, the shot was dropped 5 times from a height of $1.78 \mathrm{~m}$ on spot 1 of the EBP. Each KE value at hit (recorded in Joules by the manufacturer's software) was projected on the screen of an attached PC. Following that, the shot was dropped 5 times from the same height on spot 2 . The same procedure was followed for the remaining spots (3-10) on the EBP. After a 30 min interval the procedure was repeated once more. The same procedure was also applied for heights $1.92 \mathrm{~m}$ and $2.00 \mathrm{~m}$. A total of 100 trials were performed for each height of release and a total of $300 \mathrm{KE}$ values were recorded by the manufacturer's software. The EBP's sensor sensitivity threshold was set at the level of minimum impact for the lowest weight class of athletes.

\section{Data processing and analysis}

The PE of the $4 \mathrm{~kg}$ shot for each height of release was calculated according to the formula PE=m.g.h, where: $\mathrm{m}$ was the $4 \mathrm{~kg}$ mass, $\mathrm{g}$ the acceleration constant $(9.81 \mathrm{~m} . \mathrm{sec} 2)$, and $\mathrm{h}$ the respective height of release $(\mathrm{m})$. Assuming vacuum conditions (i.e. negligible air resistance during fall) the PE at release is totally transformed to KE at strike and calculated with the formula: KE at strike $=(1 / 2) \mathrm{m} . \mathrm{v} 2$. The KE for each of the 300 trials was then calculated and compared with the respective values calculated by the manufacturer's devise. The linearity of the device was assessed by overall and 10 separate calibration curves computed via linear regression (one for each of the 10 tested sites). The reliability (Hopkins 2000, Del Vecchio et al., 2011) was assessed (a) by means of the test-retest method using Chronbach's alpha, Guttman split half, and ICC, and (b) the typical percentage variation (\%CV).

\section{RESULTS}

The device exhibited a highly unstable bias in estimating the KE values at impact (table 1). Striking differences were observed between the estimated and the recorded KE mean values, thus resulting in a non-constant bias ranging from about $98 \%$ to $104 \%$. Furthermore, the pattern of variation appeared to be unstable while the coefficients of variation between the three heights of release were inconsistent $(5.46 \%$, $4.72 \%, 4.23 \%)$.

\section{Static Calibration Estimates}

Eleven calibration curves were produced in correspondence to the overall and the 10 sites of the EBP device to depict the degree of agreement (linearity) between the estimated and the 10-trial average recorded KE for each of the three heights of release. The overall calibration curve (all 10 sites pooled together) showed good linearity statistically $(Y=1.4392 X+41.406, R 2=0.9715$; Figure 3$)$. The points produced by the three plotted pairs of data grossly coincided with the line of fit and the common variance between expected and recorded kinetic energy was greater than $97 \%$. However, the individual calibration curves of the 10 tested sites of the EBP device produced mostly unacceptable calibration curves. More specifically, with the exception of sites 4 and 9 , which demonstrated good linearity, sites $5 \& 6$ presented moderate linearity, sites 2 and 10 low linearity, site 3 a reversed negative linearity, site 1 an unstable linearity, and sites 7 and 8 no linearity at all. The respective \% common variance ranged from a maximum of $99.27 \%$ (site 9 ) to a minimum of $0.98 \%$ (site 7 ). 
Table 1. Estimated and recorded (by the device) kinetic energy parameter

\begin{tabular}{|c|c|c|c|c|c|c|}
\hline \multirow{2}{*}{$\begin{array}{l}\text { Height of } \\
\text { Release } \\
\text { (m) }\end{array}$} & \multirow{2}{*}{$\begin{array}{l}\text { Potential } \\
\text { Energy } \\
\text { (Joules) }\end{array}$} & \multirow{2}{*}{$\begin{array}{l}\text { Time to } \\
\text { contact } \\
\text { (sec) }\end{array}$} & \multirow{2}{*}{$\begin{array}{l}\text { Impact } \\
\text { Velocity } \\
\text { (m/sec) }\end{array}$} & \multirow{2}{*}{$\begin{array}{c}\text { EBP recorded Kinetic } \\
\text { Energy (Joules) } \\
\text { Mean (SD, \%CV) }\end{array}$} & \multicolumn{2}{|c|}{ Systematic Bias } \\
\hline & & & & & Absolute & $\%$ \\
\hline 1.78 & 69.847 & 0.602 & 5.91 & 142.38 & & \\
\hline & & & & $( \pm 7.77,5.46)$ & 72.533 & 103.8 \\
\hline 1.92 & 75.341 & 0.626 & 6.14 & $\begin{array}{c}148.61 \\
( \pm 7.01,4.72)\end{array}$ & 73.269 & 97.24 \\
\hline 2.00 & 78.480 & 0.639 & 6.26 & $\begin{array}{c}155.14 \\
( \pm 6.57,4.23)\end{array}$ & 76.66 & 97.68 \\
\hline
\end{tabular}

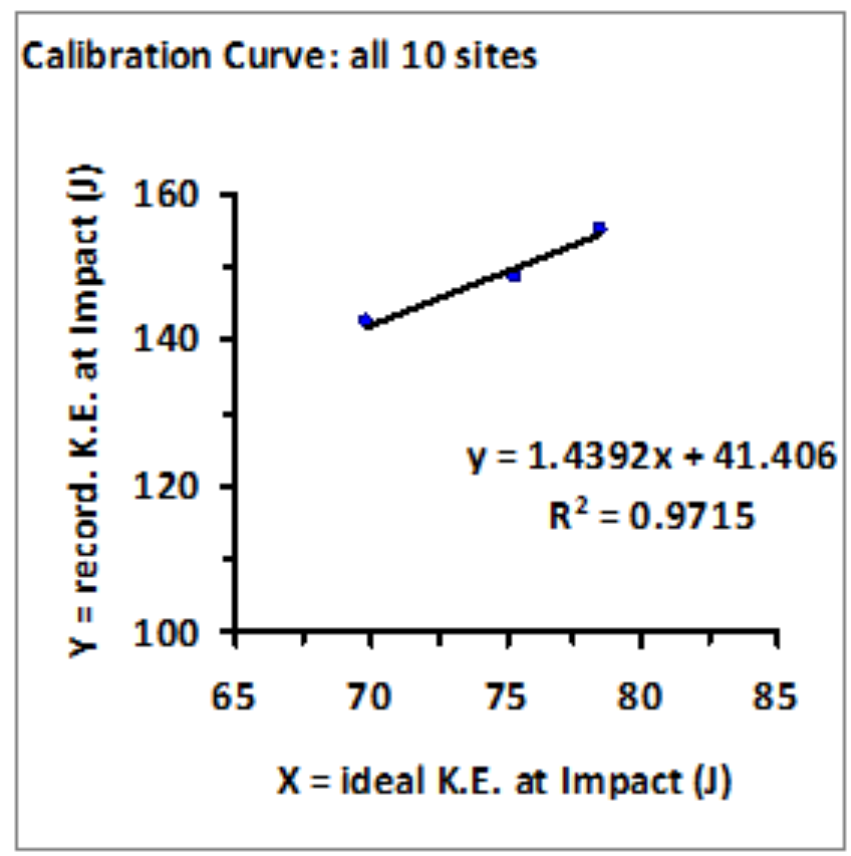

Figure 3. Overall calibration curve (line of fit) between estimated and recorded kinetic energy (each point represents a height of release: $1.78 \mathrm{~m}, 1.92 \mathrm{~m}, 2.00 \mathrm{~m}$ ). 


\section{Reliability Analysis}

The overall (10 sites pooled together) CV was $4.8 \%$. More specifically the CV's for the height of release $1.78 \mathrm{~m}, 1.92 \mathrm{~m}$, and $2.00 \mathrm{~m}$ were $5.47 \%, 4.77 \%$, and $4.18 \%$, respectively (Figure 4). The results of the 10 separate analyses (one for each of the 10 EBP sites) showed that the CV values ranged from $2.5 \%$ (site 5 , height of release $1.78 \mathrm{~m}$ ) to $11.6 \%$ (site 1 , height of release $2.00 \mathrm{~m}$ ). Even higher levels of variation were observed for the inter-trial analysis (Figure 5). Specifically, the results of the 10 separate analyses (one for each of the 10 trials) demonstrated that the CV values ranged from $6.8 \%$ (site 2, height of release $1.78 \mathrm{~m}$ ) to $11.6 \%$ (site 6 , height of release $1.92 \mathrm{~m}$ ). Subsequent analysis revealed an overall reliability between the 30 trials (across the 3 heights of release) as follows: Chronbach's $\alpha=0.979$, single measure ICC $=0.572$, average measure ICC $=0.976$ (both significant at $p<0.001$ ).

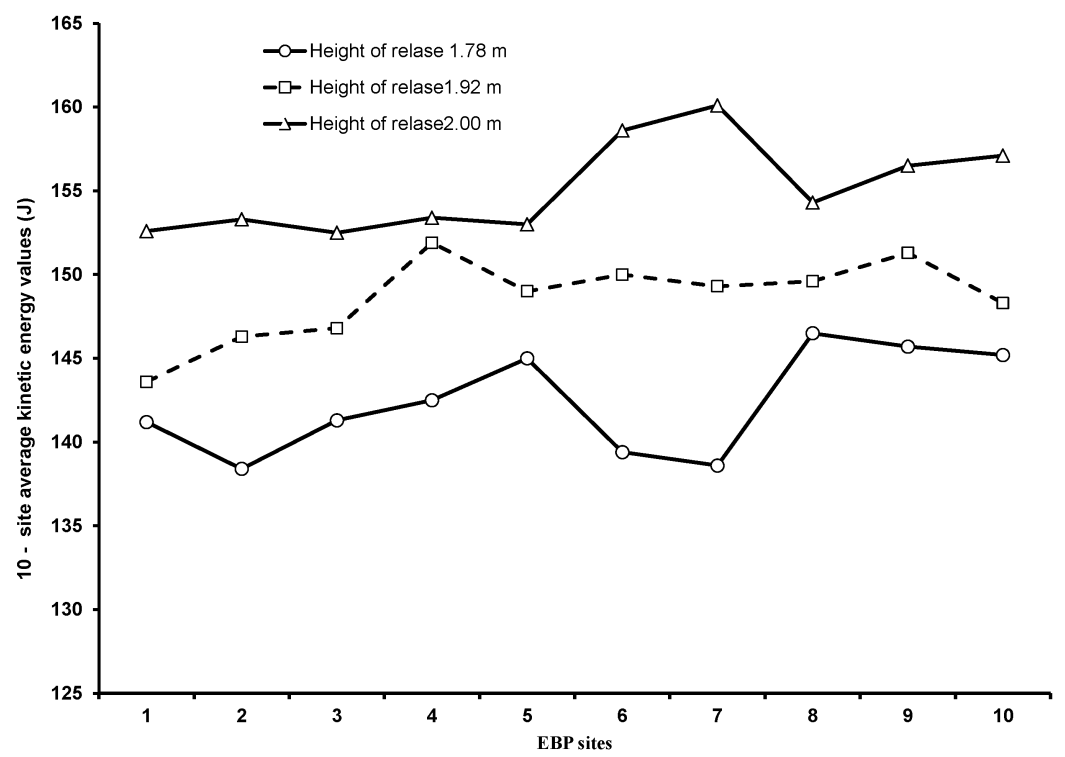

Figure 4. Inter-site series line for each height of release

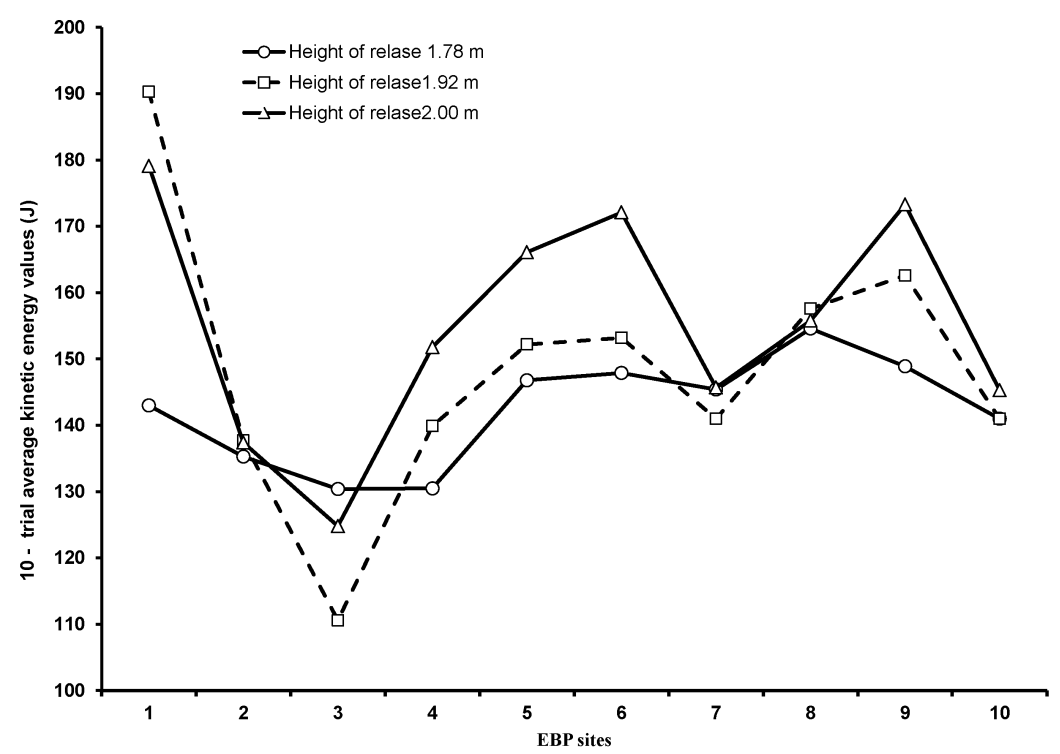

Figure 5. Inter-trial series line for each height of release (upper line: 200 m, middle line: 192 m, lower line: $178 \mathrm{~m})$. 


\section{DISCUSSION AND CONCLUSIONS}

The purpose of the study was to assess the reliability and linearity of a commercially available EBP protector and according to the results proceed to suggestions regarding its usage both in competitions and in laboratory conditions for research purposes. Regarding to its accuracy the device presented a highly unstable bias in recording the kinetic energy values applied. Prominent differences and a systematic deviation were observed between the potential (criterion value) and the actually recorded kinetic energy mean values. It appears that this EBP device's validity to accurately capture the input criterion kinetic energy at impact for each of the three heights of release is not supported by our results. Additionally, the pattern of variation also seemed to be unstable as the coefficients of variation were inconsistent between the three heights of release $(5.46 \%, 4.72 \%, 4.23 \%)$. Overall the majority of the EBP's tested areas provided inaccurate readings and their threshold for registering the energy of the hit was not acceptable and may not be appropriate for use in official competitions.

In regards to reliability inherent to this EBP device, a careful inspection of the results leads to the descriptive conclusion that (a) the inter-trial reliability is poor and characterized by a slight trend of deterioration especially towards the middle to end of the trials phase, whereas (b) the inter-site reliability is even worst with the three line intersecting each other at some sites (i.e. site 2) instead of being even grossly horizontal. If the device was perfectly reliable then the three lines in each of these two graphs should have been perfectly horizontal. The reliability assumption in this study was based on the concept of inter-trial agreement (error within trials) and it was assessed by two traditional methods (Atkinson \& Nevil, 1998, p. 227-230): (a) the coefficient of variation (CV) or typical \% error as an index expressing the absolute reliability of the device and (b) the intraclass correlation coefficient (ICC) as an index expressing the test-retest performance of the device. The typical percentage error is calculated as the $\%$ ratio between the standard deviation of the repeated measurements and their mean. The subsequent analysis of the EBP's test-retest reliability revealed an overall satisfactory reliability between the 30 trials (across the 3 heights of release) as with the exception of the Guttman split half value of 0.410 and the single measure ICC of 0.436 for height of release 1.78, the test-retest reliability results were at acceptable levels. However, these findings could be misleading considering the large variation values of the typical percentage error $(\% \mathrm{CV})$ found in the analysis. In addition, these reliability results are questionable on the basis of the poor to unacceptable linearity results produced from the calibration analysis.

So far, limited data exist as to the magnitude of the force or energy values recorded in a competition. Only Del Vecchio et al. (2010) presented data of the same EBP protector during an official competition and the energy values recorded ranged from $211 \pm 34$ joules in junior $<51 \mathrm{~kg}$ TKD athletes to $262 \pm 49$ joules in senior $67-78 \mathrm{~kg}$ TKD athletes. The criterion values used in the present study ranged from 69 to 78 joules while the values actually recorded ranged from 142 to 155 joules. There must be several reasons for this overestimation. It could be that the location of the sensors in the inner surface of the device is inappropriate for testing according to the British standard protocol applied in the present study. When testing a protector with the British Standard method, its material is deforming too quickly to attenuate the consecutive rigid impacts of the sphere, and/or the contact time on the hit surface during the impact is too small to trigger a threshold effect on the transmission of the sensors (Tsui and Pain 2009). In a typical use where the viscoelastic nature of the contestants' foot and body as well as the larger contact area of the foot allows for higher contact times and better transmission of the sensors (Tsui and Pain 2009). A TKD contest consists of 3 rounds lasting 3 minutes ("dead" time not included) each. According to Santos et al. (2011) the offensive or defensive kicks and punches during a contest present a frequency of approximately 1 every 8 10 seconds. Del Vecchio et al. (2011) reported that body protectors are manufactured to receive 
approximately 5 blows per second. In the present study the frequency of blows enacted on the EBP was 10 throws within roughly 2 minutes. This corresponds to 1 blow per 12 seconds which is in line with the suggested use of a body protector. The only difference is that in the present study the hits where applied consecutively on the same spot. This may have had an impact on the ability of the protector's sensors to record both reliably and accurately the kinetic energy at impact. In addition to that, it might be the case that in contest conditions the time elapsed between the hits applied on the protector allows the material surrounding the sensors to regain its properties quickly.

An EBP contains piezoelectric sensors (transducers) which measure dynamic phenomena such as force, pressure and acceleration. Inside the sensor, the piezoelectric materials such as quartz and ceramics are stressed in a controlled fashion by the input measured (i.e. an athlete's kick). This pressure "squeezes" a quantity of electrical charge from the piezoelectric material proportional to the input, creating analogous electrical output signals (Tichy \& Gautschi 1980; Gautschi 2002). The quantity of charge generated by a piezoelectric transducer is measured in units of picocoulombs $(\mathrm{pC})$ which is $10-12 \mathrm{C}$. The respective EBP records joules, which is the work required to move an electric charge of one coulomb through an electrical potential difference of one volt. The EBP has to transfer the information, contained within the small amount of electrical charge generated by the piezoelectric sensing element, to the display screen without dissipating it. Although piezoelectric force transducers show a good dynamic behaviour, static sensor qualities, such as linearity, sensitivity, reproducibility and effects of mechanical disturbance properties, which are necessary for precision measurements, are widely unknown (Kumme et al., 2001; Mack 2001). Two factors may affect the output of an EBP. Firstly, the polarity of the voltage generated depends on the atomic structure of the material. Sequentially, as a result of finite insulation resistance, the induced charges may present an exponential decrease as any leakage path would let electrons redistribute across the material, dropping the voltage output back to zero. Secondly, the direction in which the force is applied. Although a force component (i.e. a direct kick or punch) may act simply in the normal direction of a force transducer, shear forces and bending moments are produced due to deflections of the EBP under load. If the force transducers are sensitive enough to these influence quantities and no calibration process is available, measurement errors will result (Mack 2006). As far as we know, the EBP in question does not use any calibration procedure prior to its usage for normalising these sources of potential variability.

EBPs where produced in to achieve accurate scoring without the subjective judgement of a referee. One issue that needs to be addressed is what constitutes valid scoring. According to WTF regulations "a scoring kick must be delivered accurately and powerfully to the legal scoring of the body". A possible explanation for the bias observed maybe that the sensors-amplifier system of the respective EBP may have been designed to record only escalating ranges of forces according to the contestant's weight categories. Undoubtedly, this is far better from the subjective and sometimes biased decision of a referee, however, does not address the issues described before. Unfortunately, as no information was available by the manufacturer regarding the technical characteristics of the EBP's structure only speculations can be made about these issues. Unless the device is designed to secure an inherent amplification of the signal for the purpose of detecting the smallest possible kinetic energy inputs (kick), both under acceptable standard methods of measurement and during TKD competition, this level of unstable bias is totally unacceptable, as proper calibration procedure for eliminating it may not be practically feasible for this type of linear device.

\section{Conclusion}

The results of this study provide important information regarding the use of EBPs as a tool to register the score during TKD performance but also as a scientific tool. Our data suggest that the respective EBP does not present the necessary accuracy, reliability and linearity for the unit of measurement used (joules) for 
assessing a standardised hit. It should be stressed though, that the device has been developed primarily for circumventing the potential bias of the judges. Further research is required in testing a variety of body protectors in conditions that mimic their typical use. Certain methodological characteristics and conditions of our study could be improved in order to solve this problem. For example the height of release of the sphere could be increase so as the potential kinetic energy values to correspond approximately to those recorded in actual competition. Future studies may (a) test an adequate number of these devices and most importantly (b) estimate more complete calibration curves by (i) increasing the number of inputs (i.e at least 10) and (ii) applying both traditional methods used in calibrating linear devices (Doebelin, 1975, p.56). This requires the use of an impact tester simulating the volume and surface of the kicking leg acting on a BOB dummy in standardised velocities and impact forces encountered in competition conditions (Del Vecchio et al., 2011). This would permit to test both the internal and external validity of the EBP's. Although the protectors may not be adequate for laboratory testing, however, they should be capable to retain a minimum level of accuracy that guarantees fairness among contestants in competition.

\section{AKNOWLEDGEMENTS}

The author would like to thank Professor Georgios Vagenas for his assistance in the statistical analysis and Associate Professor Harilaos Tsolakis and Lecturer Apostolos Theodorou for their assistance in data collection.

\section{REFERENCES}

1. Automotive Industry Action Group (AIAG) (2005). Statistical Process Control. 2nd ed. Southfield, Ml: Author.

2. ATKINSON G, NEVILL AM. Statistical methods for assessing measurement error (Reliability) in variables relevant to sports medicine. Sports Med. 1998; 26(4): 217-238.

3. BAO L, INTILLE SS. Activity recognition from user-annotated acceleration data, In Proceedings of PERVASIVE 2004, vol. LNCS 3001, A. Ferscha and F. Mattern, Eds. Berlin Heidelberg: SpringerVerlag, 2004, pp. 1-17. 2004.

4. BOBBERT MF, VAN SOEST AJ. Effects of muscle strengthening on vertical height: A simulation study. Med Sci Sport Exer. 1994; 26: 1012-1020.

5. BRITISH STANDARDS (2000). BS EN13277-3: 2000

6. CHI EH, SONG J, CORBIN G. "Killer app" of wearable computing: wireless force sensing body protectors for martial arts, In UIST '04: Proceedins of the 17th annual ACM symposium on User interface software and technology. New York, NY, USA: ACM Press pp 277-285. 2004.

7. CHIU PH, WANG HH, CHEN YC. Designing a measurement system for Teakwondo training, In XXI ISB Congress, July 1-5, Taipei, Taiwan. J Biomech. 2007; 40 (Suppl. 2): S619.

8. CRONIN JB, HONG RD, MCNAIR PJ. Reliability and validity of a linear position transducer for measuring jump performance. J Strength Cond Res. 2004; 18: 590-593.

9. DEL VECCHIO FB, FRANCHINI E, DEL VECCHIO AHM, PIETER W. Energy absorbed by electronic body protectors from kicks in a taekwondo competition. Biol Sport. 2011; 28: 75-78.

10. DEMPSTER WT, GAUGHRA, GRL. Properties of body segments based on size and weight. Am J An. 1967; 120: 33-54. doi: 10.1002/aja.1001200104

11. DOEBELIN E0. Measurement systems. Application and Design. New York: Mc Graw-Hill Book Company/ 1975

12. GAUTSCHI G. Piezoelectric Sensorics. Springer Verlag: Berlin Heidelberg/2002

13. GRAY L. Force and impact determinations of certain karate kicks. J Biom. 1979;12(8): 636-637. 
14. HAEMAELAEINEN P, ILMONEN T, HOEYSNIEML J, LINDHOLM M, NYKAENEN A. Martial arts in artificial reality, in $\mathrm{CHI}$ '05: Proceedins of the SIGCHI conference on Human factors in computing systems. New York, NY, USA: ACM Press pp 781-790. 2005.

15. HEINZ EA, KUNZE KS, SULISTYO S, JUNKER H, LUKOWICH P, TROSTER G. Experimental evaluation of variations in primary features used for accelerometric context recognition. In Proceedings of the 1st European Symposium on Ambient Intelligence (EUSAI 2003). E. Aarts, R.Collier, Van Loenen B de Ruyter (eds) LNCS 2875, Springer-Verlag, pp. 252-263. 2003.

16. HOPKINS WG. Measures of reliability in sports medicine and science. Sport Med. 2000; 30(1): 115.

17. JAKIUBIAK N, SAUNDERS DH. The feasibility and efficacy of elastic resistance training for improving the velocity of the Olympic Taekwondo turning kick. J Strength Cond Res. 2008; 22(4): 1194-1197.

18. JIFOVTSEFF B, CRIELAARD JM, CAUCHY S, CROISIER JL. Validity and reliability of an inertial dynamometer using accelerometry. Sci Sport. 2008; 23: 94-97.

19. KAZEMI M, PERRI G, SOAVE D. A profile of 2008 Olympic Taekwondo competitors. J Can Chiropr Assoc. 2010; 54(4): 243-249.

20. KERN N, SCHIELE B, SCHMIDT A. Multi sensor activity context detection for wearable computing, In Proceedings of the 1st European Symposium on Ambient Intelligence (EUSAI 2003), E. Aarts, R.Collier, Van Loenen B de Ruyter (eds) LNCS 2875, Springer-Verlag. 2003.

21. KUMME R, MACK O, BILL B, HAAB HR, GOSSWEILER C. Investigation of Piezoelectric Force Measuring Devices in Force Calibration and Force Standard Machines, In Proceedings of the 17th Intl. Conference on Force, Mass, Torque and Pressure Measurement, IMEKO TC3. Istanbul, Turkey. 2001.

22. MACK 0 . New procedures to characterise drift and non-linear effects of piezoelectric force sensors, In Proceedings of the IMEKO TC3 Conference. Istanbul, Turkey. 2001.

23. MACK O. A new calibration method with static loads for piezoelectric force transducers, In XVIII IMEKO WORLD CONGRESS, Metrology for a Sustainable Development. Rio de Janeiro, Brazil. 2006

24. MATSUSHIGUE KA, HARTMANN K, FRANCHINI E. Taekwondo: Physiological responses and match analysis. J Strength Cond Res. 2009; 23(4): 1112-1117.

25. NAVARRO M, MIYAMOTO N, RANVAUD R. Analise de sistemade validacao de pontos no Taekwondo. Rev. Bras.Ed.Fis Esporte. 2008; 22: 193-200.

26. O'SULLIVAN DO, CHUNG C, LEE K, KIM E, KANG S, KIM T, SHIN I. Measurement and comparison of Taekwondo and yongmudo turning kick impact force for two target heights. J Sport Sci Med. 2009; 8(CSSI III): 13-16.

27. PIETER W, HEIJMANS J. Scientific coaching for Olympic Taekwondo (2nd ed.). Oxford, United Kingdom: Meyers and Meyers Sport/2000

28. PIETER F, PIETER W. Speed and force in selected Taekwondo techniques. Biol Sport. 1995; 12 : 257-266.

29. SANTOS VGF, FRANCHINI E, LIMA-SILVA AE. Relationship between attack and skipping in Taekwondo contests. J Strength Cond Res. 2011; 25(6): 1743-1751.

30. SERINA RE, LIEU KD. Thoracic injury potential of basic competition Taekwondo kicks. J Biom. 1991; 24: 951-960.

31. SIDTHILAW S. Kinetic and kinematic analysis of Thai boxing roundhouse kicks. Doctoral Thesis, Oregon State University. 1996 
32. SONG Y, JEON Y, PARK G, AN H, HWANG T, LEE H, LEE S. Development of Taekwondo Trainer System for Training on Electronic Protector with Hitting Target Indicator. Int J Comp Sci Net Sec. 2010; 10(6): 51-56.

33. SMITH RR, MCCRARY SW, CALLAHAN RN. Gauge repeatability and reproducibility studies and measurement system analysis: A multi method exploration of the state of practice. J Qual Tech. 2007; 23(1): 1-11.

34. TICHY J, GAUTSCHI G. Piezoelektrische Messtechnik. Springer Verlag: Berlin Heidelberg. 1980.

35. TSUI F, PAIN MTG. The effects of testing technique on the performance of chest protectors in tae kwon do, In 32nd Annual Meeting of the American Society of Biomechanics. Penn State: USA. 2009

36. WALSH MS, FORD KR, BANGEN KJ, MYER GD, HEWETT T. E. The validation of a portable force plate for measuring force-time data during jumping and landing tasks. J Str Cond Res. 2006; 20: 730-734. 